\title{
Características biométricas, anatômicas e fisiológicas de Artemisia vulgaris L. cultivada sob telas coloridas
}

\author{
OLIVEIRA, M.I. ${ }^{1}$; CASTRO, E.M. ${ }^{1}$; COSTA, L.C.B. ${ }^{2 *}$; OLIVEIRA, C. ${ }^{1}$ \\ 1UFLA, Depto. de Biologia, Lavras, MG, 37200-000, emcastro@ufla.br; 2UESC, Depto. de Ciências Biológicas, \\ Ilhéus, BA, 45662-000, *larissacbc@uol.com.br
}

\begin{abstract}
RESUMO: O uso de telas coloridas representa um novo conceito agrotecnológico, que pretende combinar a proteção física das plantas com a filtragem seletiva da radiação solar para promover respostas fisiológicas desejáveis, reguladas pela luz. O objetivo deste trabalho foi verificar o efeito do sombreamento com telas coloridas sobre características biométricas, anatômicas e fisiológicas de Artemisia vulgaris. As plantas foram cultivadas em vasos distribuídos inteiramente ao acaso sob os tratamentos de tela colorida tipo Cromatinet (50\%) vermelha, azul e pleno sol (sem tela). Os resultados indicam que as variáveis analisadas de $A$. vulgaris foram mais afetadas pela intensidade luminosa do que pela qualidade espectral da luz. O diâmetro do caule e 0 número de grãos de amido foram indiferentes aos tratamentos, enquanto as variáveis altura, relação raiz:parte aérea, espessura foliar, teor de clorofila e carotenóides foram influenciadas pela intensidade luminosa. A área foliar, a biomassa seca da planta e o número de cloroplastídeos foram afetados tanto pela intensidade quanto pela qualidade do espectro luminoso incidente.
\end{abstract}

Palavras-chave: Artemisia vulgaris, plantas medicinais, intensidade de luz, qualidade de luz

\begin{abstract}
Biometric, anatomical and physiological aspects of Artemisia vulgaris L. grown under colored screens. The use of colored screens represents a new agricultural concept, which combines the plant physical protection with the solar radiation selective filtration to obtain expected light-regulated physiological responses. The aim of this work was to verify the effect of shading using colored screens on biometric, anatomical and physiological characteristics of Artemisia vulgaris. Plants were grown in pots kept in a completely randomized distribution, and treatments consisted of red and blue Cromatinet-type (50\%) screens, besides full sun (without screen). The studied variables were more affected by light intensity than by light spectral quality. Stem diameter and starch grain number were not influenced by treatments, whereas height, root:shoot ratio, leaf thickness, and chlorophyll and carotenoid content were influenced by light intensity. Leaf area, plant dry matter and chloroplast number were affected by both light intensity and spectral quality.
\end{abstract}

Key words: Artemisia vulgaris, medicinal plants, light intensity, light quality

\section{INTRODUÇÃO}

Artemisia vulgaris L. (Asteraceae), popularmente conhecida como absinto ou losna, é uma espécie aromática, herbácea, perene e rizomatosa originária da Europa ou Ásia. Na medicina popular é reconhecida por seus efeitos analgésicos, antiespasmódicos e anticonvulsivos, sendo empregada também para dispepsia, astenia, epilepsia, dores reumáticas, febres, anemias e como vermífugo. Na composição química destacam-se o óleo essencial rico em terpenos (cineol e tuiona), flavonóides, taninos, saponinas, resinas, princípios amargos e artemisina que vem sendo testada com resultados promissores contra malária (Lorenzi \& Matos, 2003).

A luz é um fator ambiental de fundamental importância para as plantas devido à ação direta ou

Recebido para publicação em 06/12/2007

Aceito para publicação em 13/10/2008

Rev. Bras. PI. Med., Botucatu, v.11, n.1, p.56-62, 2009. 
indireta na regulação do crescimento e desenvolvimento vegetal. As adaptações sofridas pelas plantas na maquinaria fotossintética em resposta às condições de luminosidade ambiental refletem em seu crescimento global (Engel \& Poggiani, 1991). A luz influencia a anatomia foliar tanto nos primeiros estádios de desenvolvimento quanto na fase adulta, pois a folha é um órgão bastante plástico e a estrutura interna adapta-se às condições de luz do ambiente. A influência da luz sobre a anatomia foliar pode ser avaliada de acordo com a intensidade, qualidade e quantidade da luz (Boardman, 1977). Apesar da confirmação dos efeitos da qualidade espectral sobre as plantas, as respostas são muito variáveis em função das espécies (Kim et al., 2004). Portanto, a utilização efetiva de filtros espectrais como reguladores do crescimento de plantas depende do conhecimento de quais faixas do espectro estão envolvidas nas respostas de crescimento de cada planta (McMahon \& Kelly, 1995).

Pode-se estabelecer diferentes condições de cultivo pela manipulação da intensidade e qualidade espectral através da utilização de telas coloridas. Vantagens específicas são obtidas com a utilização de telas diferenciadas, que exercem pequena interferência no microclima, mas modificam a intensidade e a composição da luz transmitida para as plantas, melhorando 0 rendimento dos cultivos (Oren-Shamir et al., 2001).

Neste contexto, o principal objetivo deste trabalho foi avaliar o efeito do sombreamento com telas coloridas sobre características biométricas, anatômicas e fisiológicas de Artemisia vulgaris.

\section{MATERIAL E MÉTODO}

O trabalho foi conduzido na Universidade Federal de Lavras (UFLA), no período de dezembro de 2005 a julho de 2006, em Lavras, município situado na região Sul do Estado de Minas Gerais, a 918,87m de altitude, latitude $21^{\circ} 14^{\prime} \mathrm{S}$ e longitude 45응. Mudas de $A$. vulgaris (depósito Herbário ESAL número 20926) foram plantadas em vasos plásticos com capacidade para $3 \mathrm{~L}$ contendo substrato formado por mistura de terra de subsolo, areia e esterco bovino decomposto na proporção de 2:1:1, e submetidas aos tratamentos de sombreamento com tela colorida ChromatiNet ${ }^{\circledR} 50 \%$ vermelha, azul e pleno sol (sem tela).

As telas coloridas possuem espectros de transmitância distintos na faixa visível com densidade da malha de $50 \%$ de sombreamento na região da radiação fotossinteticamente ativa. O espectro típico da tela azul apresenta um pico principal de transmitância na região de $470 \mathrm{~nm}$ e outro acima de $750 \mathrm{~nm}$, enquanto a tela vermelha possui maior transmitância acima de 590 nm (Oren-Shamir et al.,
2001). A razão vermelho:vermelho distante (V:VD), principal fator regulatório das reações mediadas pelos fitocromos, é pouco alterada pelas telas coloridas. $O$ fator de diferenciação mais importante entre as telas é a razão azul:vermelho $(A: V)$, que é maior sob a tela azul e menor sob a tela vermelha (Shahak et al., 2006).

Após 120 dias de cultivo, selecionaram-se dez plantas ao acaso dentro de cada tratamento com as quais procedeu-se as análises biométricas de altura das plantas desde a superfície do solo até o ápice da planta e do diâmetro do caule na altura do coleto com auxílio de trena e paquímetro, respectivamente. A área foliar total foi medida utilizando-se um Medidor Eletrônico de Área Foliar Modelo LI-3100-LICOR.

Posteriormente, cada planta colhida foi particionada em raiz, caule e folha e embaladas individualmente em sacos de papel Kraft para secagem em estufa com circulação de ar forçada a $40 \pm 3^{\circ} \mathrm{C}$, até peso constante para obtenção da biomassa seca, com a qual também foi determinada a relação raiz:parte aérea.

Coletaram-se folhas do quinto nó abaixo do ápice de cinco plantas tomadas ao acaso em cada tratamento. As folhas foram fixadas em solução FAA 70 (formol, ácido acético e álcool etílico) e estocadas em solução de etanol a $70 \%$. Foram preparadas lâminas semipermanentes da região mediana do limbo foliar, a partir de seções transversais feitas à mão livre. Os cortes obtidos foram submetidos à coloração com safrablau (Kraus \& Arduin, 1997). Utilizando microscópio, equipado com uma ocular micrométrica, foram avaliadas as variáveis: espessura da epiderme das faces adaxial ( $A D$ ) e abaxial $(A B)$, parênquima paliçádico (PP), parênquima esponjoso ( $\mathrm{PE}$ ) e lâmina foliar (LF).

Para observação das características ultraestruturais dos cloroplastos foi realizada análise em microscópio eletrônico de transmissão (MET) Zeiss EM 109. As amostras foram primeiramente fixadas em solução de Karnovsky modificada por cinco dias mantidas em geladeira e pós-fixadas com tetróxido de ósmio $1 \%$ à temperatura ambiente por uma hora. A seguir foram contrastadas em bloco com acetato de uranila $0,5 \%$ por uma noite a $4^{\circ} \mathrm{C}$, depois desidratadas em gradiente de acetona a partir de $30 \%$ e, incluídas em série crescente acetona/resina Spurr, montadas em moldes e polimerizadas em estufa a $70^{\circ} \mathrm{C}$ por um dia. Os blocos obtidos foram submetidos à microtomia ultrafina utilizando-se um micrótomo Reichert Jung equipado com lâmina de diamante. $O$ material foi colhido em telas de cobre e póscontrastado com acetato de uranila $2 \%$ seguido por acetato de chumbo 1\%. Nestas secções determinouse o número e a área $\left(\mu \mathrm{m}^{2}\right)$ dos cloroplastos e grãos de amido nos cloroplastos de dez células do parênquima paliçádico, sendo cada uma considerada

Rev. Bras. PI. Med., Botucatu, v.11, n.1, p.56-62, 2009. 
como uma replicata. As imagens digitais foram obtidas utilizando-se o software de análise de imagens AnalySIS (Soft Imaging System GmbH, Münster, Alemanha) e analisadas com o software WinCELL Pro (Regent Instruments, Sainte-Foy, Quebec, Canadá).

A quantificação das clorofilas $a, b$ e total seguiu a metodologia de Arnon (1949). Com um espectrofotômetro v/uv Beckman modelo 640 B foi realizada a leitura da absorbância dos extratos a 663 $\mathrm{nm}$ e $645 \mathrm{~nm}$. Todo o procedimento foi realizado em ambiente sem luminosidade para evitar a degradação de clorofilas.

Para a extração e a quantificação dos carotenóides seguiu-se a metodologia descrita por Duke \& Paul (1986).

O delineamento experimental adotado foi o inteiramente casualizado e os dados obtidos foram submetidos à análise de variância para comparação de médias através do teste Tukey a $5 \%$ de probabilidade.

\section{RESULTADO E DISCUSSÃO}

O padrão de crescimento das plantas variou em função dos ambientes aos quais foram submetidas. As plantas expostas a pleno sol apresentaram menor altura quando comparadas às plantas submetidas aos tratamentos sombreados, os quais não foram diferentes entre si (Tabela 1). Esta resposta pode ser atribuída ao efeito da intensidade luminosa, uma vez que o rápido crescimento em altura das plantas sombreadas é um mecanismo de adaptação das plantas competitivas ou nômades (Tinoco \& Vasques-Yanes, 1985) como forma de escape ao déficit de luz, já que estas não são capazes de tolerar baixa intensidade luminosa por meio do ajuste de suas taxas metabólicas.

O maior diâmetro de caule é característica desejável em mudas porque garante maior sustentação da parte aérea. Apesar de ser uma característica de grande plasticidade para algumas espécies (Lee et al., 1997), em A. vulgaris não foi observada variação do diâmetro do caule em função dos tratamentos adotados (Tabela 1).

TABELA 1. Características biométricas de plantas jovens de Artemisia vulgaris cultivadas sob diferentes telas coloridas. UFLA, Lavras, MG, 2006.

\begin{tabular}{|c|c|c|c|}
\hline \multirow{2}{*}{ Parâmetros } & \multicolumn{3}{|c|}{ Tratamentos } \\
\hline & Pleno Sol & Azul & Vermelho \\
\hline Altura da planta $(\mathrm{cm})$ & $35,68 \mathrm{~b}$ & 122,12 a & 125,87 a \\
\hline Diâmetro do coleto $(\mathrm{cm})$ & 0,56 a & 0,57 a & 0,65 a \\
\hline Área foliar $\left(\mathrm{cm}^{2}\right)$ & $750,48 b$ & $1532,86 a$ & $950,76 \mathrm{~b}$ \\
\hline Biomassa seca das folhas $(g)$ & $7,50 \mathrm{~b}$ & $12,40 \mathrm{a}$ & $7,90 \mathrm{~b}$ \\
\hline Biomassa seca do caule $(\mathrm{g})$ & 14,43 a & $9,91 \mathrm{~b}$ & $8,11 \mathrm{~b}$ \\
\hline Biomassa seca da raiz (g) & $18,70 \mathrm{a}$ & $15,50 \mathrm{a}$ & $11,60 \mathrm{~b}$ \\
\hline Biomassa seca total $(g)$ & $22,93 \mathrm{a}$ & 21,11 a & $13,01 \mathrm{~b}$ \\
\hline raiz : parte aérea & 0,85 a & $0,69 \mathrm{~b}$ & $0,72 \mathrm{~b}$ \\
\hline
\end{tabular}

*Médias seguidas pela mesma letra, na linha, não diferem entre si pelo teste de Tukey a 5\% de probabilidade.

Quanto à área foliar, os maiores valores foram obtidos nas plantas cultivadas sob tela azul, enquanto nos demais tratamentos não houve diferença (Tabela 1). Em geral, o incremento da área foliar é uma forma da planta aumentar a superfície fotossintética, assegurando um aproveitamento mais eficiente das baixas intensidades luminosas e, conseqüentemente, compensando as baixas taxas de fotossíntese por unidade da área foliar característica de folhas de sombra (Jones \& Mcleod, 1990). Apesar das variações de área foliar normalmente estarem associadas a diferenças de intensidade luminosa, nesta espécie pode-se inferir que esta característica foi modulada pela qualidade de luz, ou seja, pela maior razão $A: V$.

As plantas cultivadas a pleno sol e sob tela azul acumularam maior quantidade de biomassa seca 
total em relação às demais (Tabela 1), mostrando que a produção de biomassa em plantas de $A$. vulgaris foi influenciada tanto pela intensidade quanto pela qualidade espectral da luz solar. A maior produção de biomassa seca total a pleno sol foi devido à maior alocação de fotoassimilados para a raiz e o caule enquanto sob tela azul a distribuição da biomassa ficou concentrada na raiz e folhas da planta. Apesar disso, Amo (1985) afirma que em condições naturais, as diferenças de luz quanto à intensidade possuem efeito mais significativo no crescimento das plantas do que a sua qualidade, principalmente no que se refere ao acúmulo de matéria seca. O maior acúmulo de biomassa seca foliar nas plantas submetidas ao sombreamento com tela azul associado à maior área foliar nesta mesma condição permite inferir que neste ambiente ocorre a maior eficiência fotossintética das plantas de $A$. vulgaris.

Variações ambientais podem causar alterações na razão raiz/parte aérea pela interferência no remanejamento e na distribuição de fotoassimilados dentro da planta. A maior razão raiz:parte aérea ocorreu em plantas submetidas a pleno sol, indicando uma alocação preferencial de matéria seca para o sistema radicular pelo efeito da intensidade luminosa (Tabela 1). Segundo Claussen (1996), plantas da mesma espécie com sistemas radiculares mais desenvolvidos em determinada condição têm maior habilidade de aclimatação, pois podem absorver maior quantidade de água e nutrientes, garantindo maior capacidade para suportar maiores taxas de fotossíntese e transpiração que ocorrem nestes ambientes.

Folhas de $A$. vulgaris são hipoestomáticas, apresentam estômatos salientes, mesofilo com estrutura dorsiventral formada por uma camada de células do parênquima paliçádico, três a quatro camadas de parênquima esponjoso, epiderme unisseriada coberta por uma espessa camada de cutícula principalmente na superfície adaxial. Devido à grande quantidade de tricomas tectores na epiderme abaxial não foi possível a determinação da densidade estomática.

As folhas das plantas cultivadas a pleno sol apresentaram maior espessura do limbo principalmente pelo aumento dos parênquimas paliçádico e esponjoso (Tabela 2). De uma forma geral, folhas de plantas cultivadas a pleno sol são mais espessas (Lee et al., 1997), com maior desenvolvimento do mesofilo e da cutícula, possuindo as células paliçádicas mais longas e justapostas (Taiz \& Zeiger, 2004). A capacidade de alterar a estrutura das folhas em resposta a diferentes níveis de luz é um atributo comum de espécies que apresentam amplo potencial de aclimatação (Björkman et al., 1972).

TABELA 2. Espessura média $(\mu \mathrm{m})$ dos componentes foliares de $A$. vulgaris submetida a diferentes espectros luminosos. UFLA, Lavras, MG, 2006.

Tratamentos

Componentes foliares

\begin{tabular}{lrrr} 
& Pleno Sol & Azul & Vermelho \\
\hline Epiderme da face adaxial & $18,15 \mathrm{ab}$ & $17,37 \mathrm{~b}$ & $18,52 \mathrm{a}$ \\
Epiderme da face abaxial & $13,98 \mathrm{~b}$ & $15,54 \mathrm{a}$ & $16,41 \mathrm{a}$ \\
Parênquima paliçádico & $62,70 \mathrm{a}$ & $54,57 \mathrm{~b}$ & $54,15 \mathrm{~b}$ \\
Parênquima esponjoso & $58,71 \mathrm{a}$ & $51,27 \mathrm{~b}$ & $47,25 \mathrm{~b}$ \\
Limbo foliar & $153,54 \mathrm{a}$ & $138,75 \mathrm{~b}$ & $136,32 \mathrm{~b}$
\end{tabular}

*Médias seguidas pela mesma letra, na linha, não diferem entre si pelo teste de Tukey a 5\% de probabilidade.

Em relação aos cloroplastídeos, observase que não sofreram variações quanto ao tamanho (Figura 1), mas sob tela vermelha houve redução do número de cloroplastídeos por células do parênquima, quando comparados às plantas à pleno sol e sob tela azul (Tabela 3). Em folhas de pimenta (Capsicum annuum L.), o número de cloroplastídeos foi maior nas plantas mantidas sob lâmpadas $\mathrm{MH}$ (controle), intermediário naquelas sob luz $660 \mathrm{~nm} / \mathrm{azul}$ e menor nas plantas cultivadas sob luz $660 \mathrm{~m}$ ou $660 / 735 \mathrm{~nm}$, comprovando que algumas alterações anatômicas quantitativas foliares estão correlacionadas com a quantidade de luz azul disponível para a planta (Schuerger et

Rev. Bras. PI. Med., Botucatu, v.11, n.1, p.56-62, 2009. 


\section{al., 1997).}

A quantidade de grãos de amido acumulados nos cloroplastídeos não variou com os tratamentos (Figura 1), entretanto, se apresentaram maiores nos tratamentos sombreados (Tabela 3). O cloroplasto produz e acumula amido, mas as suas dimensões podem variar de acordo com o período do dia, à medida que os açúcares são formados e, temporariamente, armazenados como amido (Taiz \& Zeiger, 2004). Em experimento realizado com plantas de tabaco (Nicotiana tabacum L.) verificou-se que os cloroplastos de folhas submetidas à luz vermelha apresentam mais e maiores grãos de amido do que as folhas submetidas à luz vermelha distante (Kasperbauer \& Hamilton, 1984).

Em plantas cultivadas a pleno sol, os teores de clorofilas $a$ e $b$ e total foram reduzidos em relação às plantas sombreadas que não diferiram entre si (Tabela 3). Folhas de plantas sombreadas são mais finas e possuem cloroplastos mais ricos em clorofila. Desta forma, folhas "de sombra" investem maior energia na produção de pigmentos responsáveis pela captação de energia radiante, permitindo uma otimização na utilização da intensidade de luz incidente (Björkman et al., 1972).

As plantas cultivadas sob telas apresentaram menor razão clorofila $a / b$ do que aquelas cultivadas a pleno sol (Tabela 3 ). A razão clorofila $a / b$ de maneira geral tende a diminuir com a redução da intensidade luminosa (Boardman, 1977) devido a uma maior proporção relativa de clorofila $b$ em ambientes sombreados, que pode estar associada à sua degradação mais lenta em relação à clorofila a (Engel \& Poggiani, 1991). O aumento da proporção de clorofila $b$ é uma característica importante de ambientes sombreados, uma vez que ela capta energia de outros comprimentos de onda e a transfere para a clorofila a, maximizando, assim, a captura de luz que efetivamente atua nas reações (Engel \& Poggiani, 1991). A diferença encontrada entre os teores de clorofila $a, b$ e total, bem como na razão clorofila $a / b$ nas plantas de $A$. vulgaris, evidenciam que essa espécie dispõe de diferentes estratégias no acúmulo e uso dos pigmentos fotossintéticos em diferentes condições de luminosidade.

Quanto aos teores de carotenóides, os maiores valores foram obtidos nas plantas cultivadas a pleno sol (Tabela 3). Os carotenóides são pigmentos que funcionam como fotoprotetores por meio da rápida extinção dos estados excitados da clorofila protegendo-a da fotooxidação (Taiz \& Zeiger, 2004).

As plantas jovens de $A$. vulgaris L, evidenciaram plasticidade fenotípica respondendo

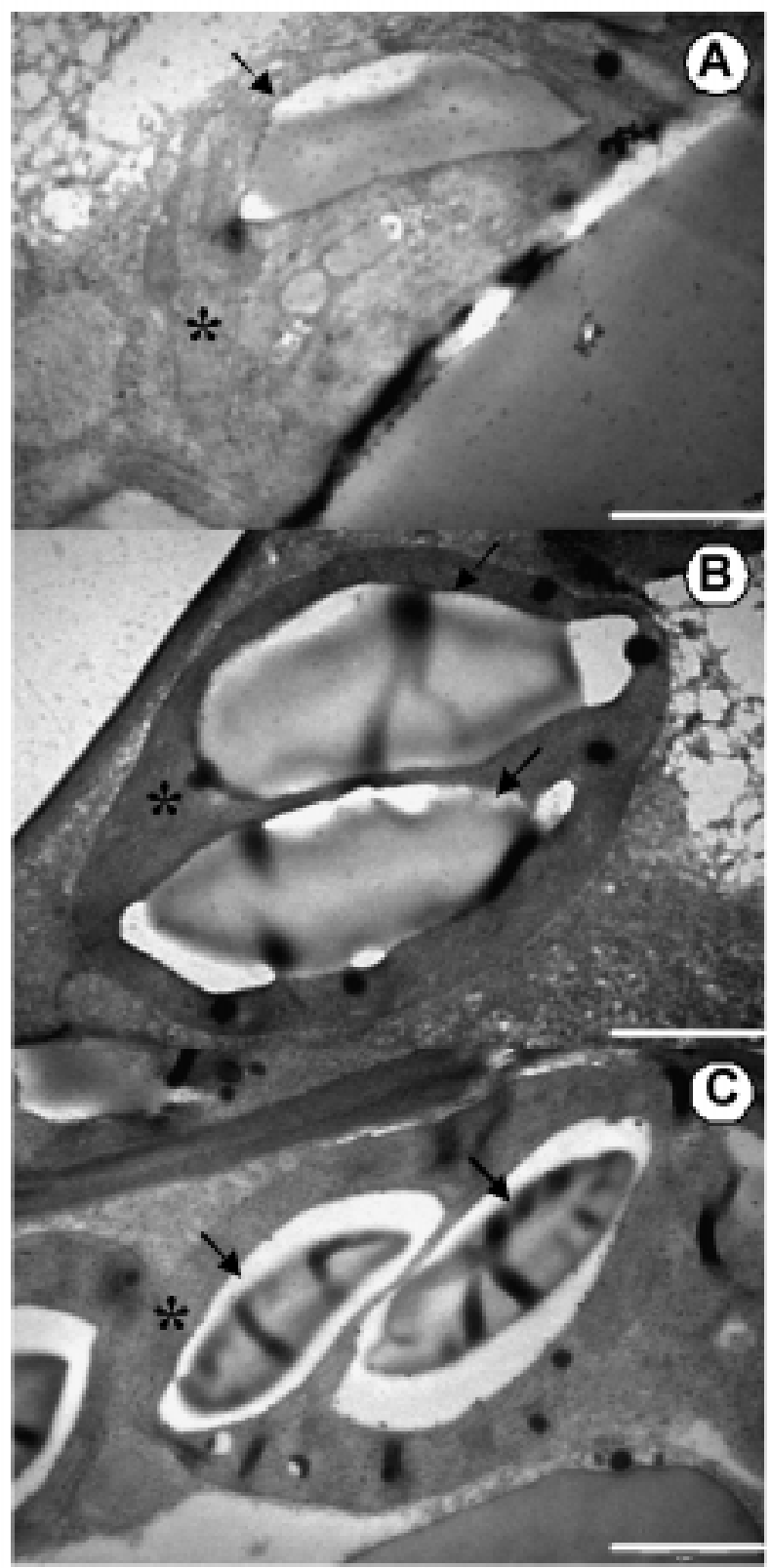

Figura 1. Cloroplastos (*) e grãos de amido (setas) nas células do parênquima paliçádico de lâminas foliares de Artemisia vulgaris submetidas a diferentes condições de sombreamento. A (pleno sol), B (tela azul $50 \%$ ) e C (tela vermelha $50 \%$ ). Barra de $1 \mathrm{~mm}$.

às variáveis analisadas diferentemente em relação aos espectros e intensidades luminosas. A altura, relação raiz:parte aérea, espessura foliar, teor de clorofila e carotenóides foram influenciados pela intensidade luminosa, enquanto que a área foliar, a biomassa seca da planta e o número de cloroplastídeos foram afetados tanto pela intensidade quanto pela qualidade do espectro luminoso incidente. 
TABELA 3. Valores médios do número de cloroplastídeos por células do parênquima paliçádico, sua área, número de grãos de amido por cloroplastídeos no parênquima paliçádico e sua área, teores de clorofila $a, b$, total, relação clorofila a/b e teor de carotenóides em $A$. vulgaris submetida a diferentes espectros luminosos. UFLA, Lavras, MG, 2006.

\begin{tabular}{|c|c|c|c|}
\hline \multirow{2}{*}{ Parametros } & \multicolumn{3}{|c|}{ Tratamentos } \\
\hline & Pleno Sol & Azul & Vermelho \\
\hline Cloroplastideos $\left(n^{2}\right.$ celula $\left.{ }^{-1}\right)$ & 10,50 & 10,85 & 7,75 \\
\hline Area Cloroplastideos $\left(\mu \mathrm{m}^{-2}\right)$ & 17,75 & 15,87 & 16,55 \\
\hline Grasos de amido ( $n^{0}$ cloroplasto $\left.{ }^{-1}\right)$ & 1,87 & 2,12 & 1,50 \\
\hline Área Grăos de amido $\left(\mu_{m}-2\right)$ & 1,50 & 3,30 & 2,25 \\
\hline Clorofila a ( $\left.\mu g g^{-1} M F\right)$ & $59,43 \mathrm{~b}$ & 73,98 a & 78,55 a \\
\hline Clorofila $b\left(\mu g g^{-1} M F\right)$ & $25,33 b$ & $42,45 \mathrm{a}$ & 41,29 a \\
\hline Clorofila total ( $\left.\mu_{g} g^{-1} M F\right)$ & $84,76 \mathrm{~b}$ & $116,43 \mathrm{a}$ & $119,84 \mathrm{a}$ \\
\hline Relaçăo clorofla $a / b$ & $2,34 \mathrm{a}$ & $1,74 \mathrm{~b}$ & $1,91 \mathrm{~b}$ \\
\hline Carotenoides ( $\mu g g^{-1} M F$ ) & 2611,91 a & $1905,76 \mathrm{~b}$ & $1701,64 \mathrm{~b}$ \\
\hline
\end{tabular}

*Médias seguidas pela mesma letra, na linha, não diferem entre si pelo teste de Tukey a $5 \%$ de probabilidade.

\section{REFERÊNCIA}

AMO, S.R. Alguns aspectos de la influencia de la luz sobre el crescimiento de estados juveniles de espécies primarias, In: GOMES-POMPA, A.; AMO, S.R. Investigaciones sobre la regeneracion de selvas altas em Vera Cruz, México. México: Instituto Nacional de investigações sobre recursos bióticos. Ed. Alhambra Mexicana \& A., 1985. p.79-92.

ARNON, D.I. Copper enzymes in isolated chloroplasts: polyphenoloxydase in Beta vulgaris. Plant Physiology, v.24, n.1, p.1-15, 1949.

BOARDMAN, N.K. Comparative photosynthesis of sun and shade plants. Annual Review Plant Physiology, v.28, p.355-77, 1977.

BJÖRKMAN, O. et al. Effect of light intensity during growth of Atriplex patula on the capacity of photosynthetic reactions, chloroplast components and structure. Carnegie Institution of Washington Yearbook, v.71, p.115-35, 1972.

CLAUSSEN, J.W. Acclimatation abilities of three tropical rainforest seedlings to an increase in light intensity. Forest Ecology and Management, v.80, n.1/3, p.245-55, 1996.

DUKE, S.O.; PAUL, R.N. Effects of dimethazone (FMC57020) on chloroplast development. II. Ultrastructural effects in cowpea (Vigna unguiculata L.) primary leaves. Pesticide Biochemistry and Physiology, v.25, p.1-10, 1986.

ENGEL, V.L.; POGGIANI, F. Estudo da concentração de clorofila nas folhas e seu espectro de absorção de luz em função do sombreamento em mudas de quatro espécies florestais nativas. Revista Brasileira de Fisiologia Vegetal, v.3, n.1, p.39-45, 1991.
JONES, R.H.; MCLEOD, K.W. Responses to a range o light environments in Chinese Tallowtree and Carolina Ash seedlings. Forest Science, v.36, p.851-62, 1990. KASPERBAUER, M.J.; HAMILTON, J.L. Chloroplast structure and starch grain accumulation in leaves that received different red and far-red levels during development. Plant Physiology, v.74, p.967-70, 1984. KIM, S-J. et al. Effects of LEDs on net photosynthetic rate, growth and leaf stomata of chrysanthemum plantlets in vitro. Scientia Horticulturae, v.101, p.14351, 2004.

KRAUS, J.E.; ARDUIN, M. Manual básico de métodos em morfologia vegetal. Seropédica: Editora da UFRRJ, 1997. 198p.

LEE, D.W. et al. Effects of irradiance and spectral quality on seedling development of two Southeast Asian Hopea species. Oecologia, v.110, p.1-9, 1997. LORENZI, H.; MATOS, F.J.A. Plantas medicinais no Brasil: nativas e exóticas. Nova Odessa: Instituto Plantarum, 2003. 254p.

MCMAHON, M.J.; KELLY, J.W. Anatomy and pigments of chrysanthemum leaves developed under spectrally selective filters. Scientia Horticulturae, v.64, p.203-9, 1995.

OREN-SHAMIR, M. et al. Coloured shade nets can improve the yield and quality of green decorative branches of Pittosphorum variegatum. Journal of Horticultural Science and Biotechnology, v.76, p.35361, 2001.

SCHUERGER, A.C. et al. Anatomic features of pepper plants (Capsicum annuum L.) grown under red lightemitting diodes supplemented with blue or far-red light. Annals of Botany, v.79, p.273-82, 1997.

SHAHAK, Y. et al. Colornets: crop protection and light-

Rev. Bras. PI. Med., Botucatu, v.11, n.1, p.56-62, 2009. 
quality manipulation in one technology. Acta Horticulturae (ISHS) v.659, p.143-51. Disponível em: <http://www.actahort.org/books/659/659_17.htm>. Acesso em: 16 mai 2006.

TAIZ, L.; ZEIGER, E. Fisiologia vegetal. Porto Alegre: Artmed, 2004. p.449-84.
TINOCO, C.; VASQUEZ-YANES, C. Diferencias en poblaciones de Piper hispidus hajo condiciones de luz contratante en uma selva alta perenifolia, In: GOMEZ-POMPA, A.; AMO, S.R. (Eds.) Investigaciones sobre la regeneration de selvas altas em Vera Cruz, México. Mexico: Ed. Alhambra Mexicana, 1985. p.267-81. 